\title{
Influence of Joint Dip Angle on Seismic Behaviors of Rock Foundation
}

\author{
by \\ Lei YANG ${ }^{*}$, Yujing JIANG ${ }^{* *}$, Bo Li ${ }^{* * *}$, Shucai $\mathrm{LI}^{* * * *}$ and Yang GAO ${ }^{*}$
}

\begin{abstract}
The seismic response of rock foundation to seismic loads is an important issue to the stability and safety of nuclear power plants. Due to the fact that the discontinuities like joints existing in the rock mass govern principally the deformation and failure behaviors of the rock mass, the influence of discontinuities on the seismic behaviors of rock mass remains as one of the fundamental problems in the safety assessment of nuclear power plants. In this study, the distinct element method (DEM) and finite element method (FEM) were adopted to investigate the seismic responses of rock foundation to a real seismic wave, taking into account the effect of joint dip angle on the deformation and dynamic behaviors of rock foundation. In the DEM simulations, the intact rock has an amplification effect on the amplitudes of seismic waves, while the joints exhibit an attenuation effect on the seismic waves. In the FEM simulations, however, the attenuation effect of joints is not obvious. The dip angle of joints has strong effects on the deformation and dynamic behaviors of rock foundation, in terms that different dip angles lead to obviously different deformation and horizontal stress in the rock foundation when subjected to seismic load. When the dip angle of joints is around $60^{\circ}$, the seismic velocity, displacement and stress reach the maximums. Therefore, attentions need to be paid on this factor during the seismic design of nuclear power plants.
\end{abstract}

Key words : Rock foundation, Seismic behavior, Dip angle of joint, Deformation, Distinct element method (DEM), Finite element method (FEM).

\section{Introduction}

There are currently 440 nuclear reactors in operation worldwide, about $20 \%$ of which are operating in the areas of significant seismic activity ${ }^{1)}$ The seismic resistance performance of nuclear power plants remains as one of the crucial issues, concerning the safety of nuclear power plants. The accidents of nuclear power plants due to earthquakes have caused great harm to the environment and human society. For example, some parts of the Kashiwazaki-Kariwa nuclear power plant were severely damaged during the M6.8 Chuetsu offshore earthquake happened in Niigata (July $16^{\text {th }}, 2007$ ), leading to the leakage of radioactive materials. The M9.0 Great Tohoku Earthquake happened in the northeast of Japan (March 11 ${ }^{\text {th }}, 2011$ ), with the succeeding tsunami, hit the Fukushima Daiichi nuclear power plant, resulting in explosion of nuclear units and radioactive releases. Lessons from those accidents indicate that nuclear facilities must be designed based on criteria far more stringent than those applying to nonnuclear facilities so that earthquakes and other external events will not jeopardize their safety.

To improve the seismic resistance capability, most of the nuclear power plants have been built on rock foundations to minimize seismic shaking, with some circulation pipelines buried in rock mass. Therefore, the responses of rock foundation to seismic loads affect the stability and safety of nuclear power plants to a great extent. The seismic responses of geotechnical foundations were studied initially with the simplified 1-D model, considering that seismic waves travel vertically through horizontal geotechnical layers. ${ }^{2) ~ 4)}$ In recent years, a number of numerical and theoretical researches have been performed, ${ }^{5) \sim 10)}$ demonstrating that the physico-mechanical properties of rock like the damping factor and the rock hardness, the hypocenter characteristics and the propagation path of seismic waves have significant influences on the seismic response of rock mass.

Although tremendous efforts have been put into the studies on the seismic behaviors of rock mass, there are still some issues remaining unsolved, especially in the cases with involvement of discontinuities, as results of the complexity of rock structures and the uncertainty of seismic characteristics. A mass of discontinuities like joints commonly exist in rock mass, principally governing the deformation and failure behaviors of rock mass. ${ }^{11)} \mathrm{A}$ number of researches have been carried out, focusing on the deformation of rock joints under various stress conditions (compression and shear) and its influence on the mechanical behaviors of rock mass. ${ }^{12) ~ 16)}$ Moreover, rock joints also impact on the propagation of seismic waves in terms of reflection and transmission, further affecting the seismic response of rock mass. ${ }^{17)}$ Many studies on the transmission of normally incident waves across single and multiple parallel joints reveal that rock joints have significant attenuation effects on the wave velocity, and the properties of joints (stiffness, maxi-

\footnotetext{
$\dagger \quad$ Received July 11, 2011 (C) 2012 The Society of Materials Science, Japan

* Graduate School of Science \& Technology, Nagasaki University, Bunkyo-machi, Nagasaki, 852-8521 Japan

* $\quad$ Member : Faculty of Engineering, Nagasaki University, Bunkyo-machi, Nagasaki, 852-8521 Japan

$* * * \quad$ Faculty of Engineering, Nagasaki University, Bunkyo-machi, Nagasaki, 852-8521 Japan

$* * * * \quad$ Research Center of Geotechnical \& Structural Engineering, Shandong University, Jinan, 250061 China
} 
mum allowable closure, etc.) and stress waves (amplitude and frequency) also affect the transmission coefficient of waves. ${ }^{17) ~ 19)}$ Therefore, to estimate the seismic response of fractured rock masses comprehensively, it is necessary to investigate the effect of joints on the deformation and dynamic behaviors of rock masses, especially in the cases of inclined incident waves.

The finite element method (FEM) is commonly adopted in most of the previous studies. As a method based on continuum mechanics, the FEM can hardly well represent the large deformation of discontinuities in rock. The distinct element method (DEM), capable of simulating the sliding and separation of joints, $\left.{ }^{20)} \sim 21\right)$ is effective to represent the non-linear mechanical behaviors of jointed rock masses. In this study, both the FEM and DEM were utilized to investigate the seismic responses of the jointed rock foundation under a nuclear power plant, taking into account the influence of joint dip angle on the dynamic behaviors of the rock foundation. Through the comparison of numerical results, the difference between the two methods in seismic simulations of rock mass was clarified.

\section{Properties of Rock Mass and Seismic Wave}

\section{1 Properties of Rock Mass}

The rock foundation of the objective nuclear power plant belongs to Mesozoic cumulates (conglomerate stone), containing a mass of discontinuities. The mechanical properties of intact rock were estimated by carrying out unconfined and triaxial compression tests and Brazilian test on intact rock samples taken from the objective ground, and the mechanical properties of joints were estimated by conducting normal loading tests and direct shear tests on rock samples containing single fractures, with the test results shown in Table 1 . In this site, the macro mechanical behaviors of the rock mass are strongly affected by the existing rock joints. For example, the elastic modulus of the rock mass measured through in-situ deformation tests ranges from 500 to $1700 \mathrm{MPa}$, which is much smaller than that of the intact rock.

To investigate the geometrical characteristics of joints, borehole drilling was performed at different locations in the rock foundation. Figure 1 shows two typical examples of unrolled sketches of core samples, demonstrating that the persistent joints (solid lines) with large dip angles $\left(60^{\circ}\right.$ to $90^{\circ}$ ) are prominent, with a mass of non-persistent joints (dashed lines) with small angles almost vertically intersecting the large angle joints. According to survey results of 183 core samples, the average spacing between the small angle joints (SL) is around 2 times of that of the large angle joints (SH).

\section{2 Characteristics of Seismic Wave}

Comparing to artificial waves, the real seismic waves taken from similar sites will be more representative to the situation when earthquake happens. In this study, the EW component of the seismic acceleration wave (with a
Table 1 Physico-mechanical properties of intact rock and joint.

\begin{tabular}{c|lcll}
\hline \multicolumn{2}{c}{ Parameters } & Symbols & Units & Values \\
\hline \multirow{5}{*}{ Intact rock } & Density & $\rho$ & $\mathrm{g} / \mathrm{cm}^{3}$ & 2.66 \\
& Elastic modulus & $E$ & $\mathrm{GPa}$ & 71 \\
& Poisson's ratio & $v$ & - & 0.18 \\
& Tensile strength & $\sigma_{\mathrm{t}}$ & $\mathrm{MPa}$ & 10.2 \\
& Cohesion & $c_{r}$ & $\mathrm{MPa}$ & 22.3 \\
& Friction angle & $\varphi_{r}$ & $\circ$ & 62 \\
\hline \multirow{5}{*}{ Joint } & Normal stiffness & $K_{n}$ & $\mathrm{MPa} / \mathrm{mm}$ & 31.78 \\
& Shear stiffness & $K_{s}$ & $\mathrm{MPa} / \mathrm{mm}$ & 3.22 \\
& Cohesion & $c_{c}$ & $\mathrm{MPa}$ & 0.027 \\
& Friction angle & $\varphi_{c}$ & $\circ$ & 35.9 \\
\hline
\end{tabular}
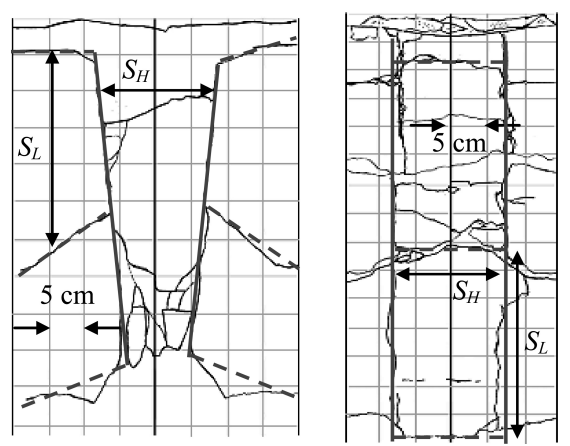

Fig. 1 Unrolled sketches of two typical core samples obtained at different locations.

larger amplitude than the NS component) measured at the Ojiya observation site during the M6.8 Chuetsu offshore earthquake (Niigata, July $16^{\text {th }}, 2007$ ) was adopted in the numerical simulations (Fig. 2). The shear wave was selected due to its great destructiveness to the rock mass and buildings. Then the time-domain seismic wave was transformed into frequency- domain wave by the fast Fourier transform to investigate the frequency characteristic. As shown in Fig. 3, this seismic shear wave presents low-frequency characteristics with the dominant frequency of $2.82 \mathrm{~Hz}$.

The seismic records obtained from observation sites represent the seismic motion of the ground surface. During earthquakes, seismic waves propagate from the deep rock formation to the ground surface. To reproduce such process in numerical simulations, it is necessary to investigate the seismic motion of the deep rock formation firstly. The code of k-SHAKE developed by the Structure and Planning Institute of Japan ${ }^{22)}$ was utilized to investigate the seismic wave at the deep rock formation with a depth of $200 \mathrm{~m}$. The propagation velocity of S-wave and the damping ratio were set as $3363 \mathrm{~m} / \mathrm{s}$ and $3 \%$ respectively, according to the results of in-situ tests. Due to the time-consuming problem of dynamic simulations, only parts of the acceleration and velocity waves, which last 10 seconds (20.8 30.8s) and contain the peak values of the total waves, were chosen as the input waves to the FEM and DEM models, respectively (Fig. 4). 


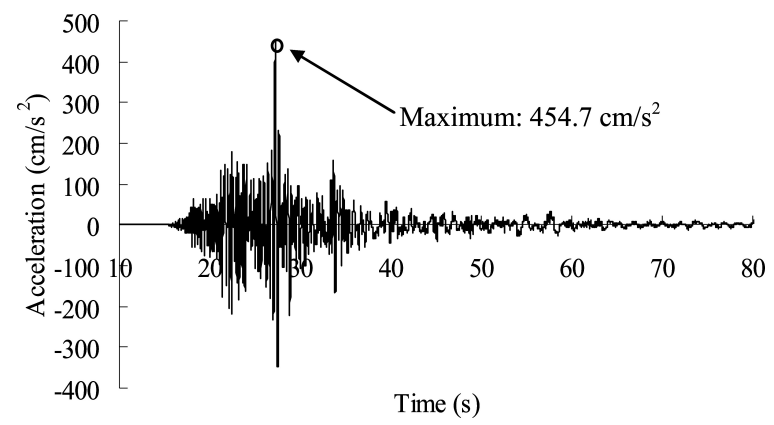

Fig. $2 E W$ component of the acceleration waves measured at the Ojiya observation site on $16^{\text {th }}$ July 2007.

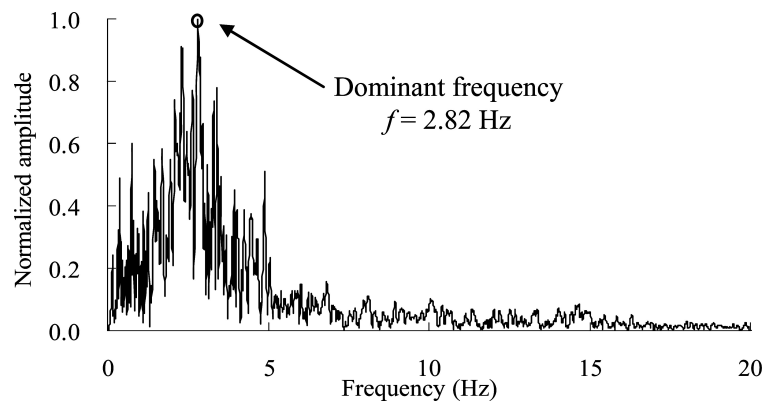

Fig. 3 Frequency spectrum of the seismic wave.

\section{Calculation Principles and Numerical Models}

\section{1 Calculation Principles of FEM and DEM}

Numerical simulations on the seismic behaviors of the rock foundation were performed by using the DEM code of UDEC ${ }^{23)}$ and the FEM code of SuperFLUSH/2D. ${ }^{24}$

In the FEM simulations, the equation of motion can be written in the discretization form of Eq.(1), where $[M]$, $[C]$ and $[K]$ denote the mass, damping and stiffness matrixes, respectively ; $\{u\}$ is the displacement vector ; $\{1\}$ is the unit vector, and $\ddot{u}_{b}$ is the input seismic acceleration. The deformations of intact rock and joints in the FEM model are involved in the identical matrix.

$$
[M]\{\ddot{u}\}+[C]\{\dot{u}\}+[K]\{u\}=-[M]\{1\} \ddot{u}_{b}
$$

The DEM represents the rock mass as an assemblage of discrete blocks and the joints as interfaces between blocks, in which the force-displacement law is used to obtain forces at interfaces from known displacements, while the Newton's second law gives the motion of blocks resulting from the known forces. ${ }^{23)}$ The motion equation of the ith block can be written in the form of central difference scheme, as shown in Eq.(2), where $t$ is time ; $\Delta t$ is time step ; $u_{i}$ is the displacement component of block centroid ; $\Sigma F_{i}$ is the total external force ; $m$ is mass ; $g_{i}$ is the gravitational acceleration ; $\theta_{\mathrm{i}}$ is the angular displacement ; $\Sigma M_{i}$ is the total moment acting on the block ; and $I$ is the moment of inertia of block.

$$
\begin{aligned}
& \dot{u}_{i}^{(t+\Delta t / 2)}=\dot{u}_{i}^{(t-\Delta t / 2)}+\left(\frac{\Sigma F_{i}^{(t)}}{m}+g_{i}\right) \Delta t \\
& \dot{\theta}_{i}^{(t+\Delta t / 2)}=\dot{\theta}_{i}^{(t-\Delta t / 2)}+\left(\frac{\Sigma M_{i}^{(t)}}{I}\right) \Delta t
\end{aligned}
$$

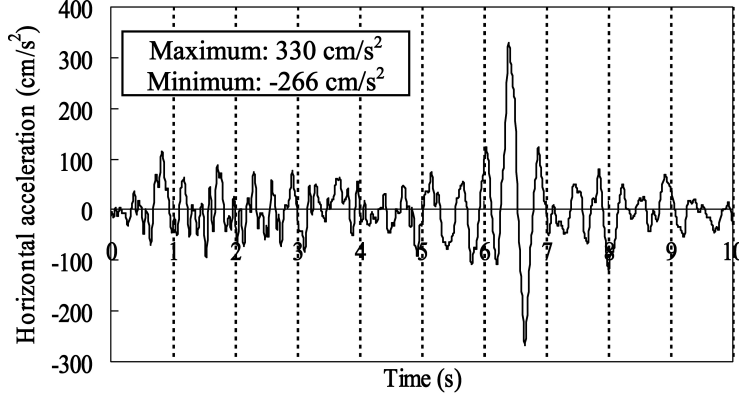

(a) Acceleration wave (for the FEM simulation)

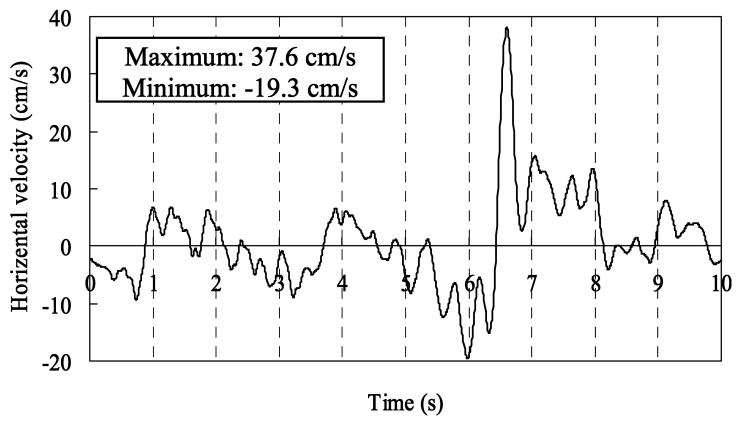

(b) Velocity wave (for the DEM simulation)

Fig. 4 Seismic waves at the deep rock formation.

In the DEM simulations, the deformation of joints depends on the external loads and the mechanical properties of joints (normal stiffness, shear stiffness, cohesion and friction angle, etc.). DEM can simulate the large deformations of joints like sliding and separation, which affects the propagation of seismic waves in terms of energy dissipation. In the DEM model, the influence of discontinuities on energy dissipation is taken into account, with the coefficients of reflection $(R)$, transmission $(T)$ and absorption (A), in the forms of Eq. (3), where $E_{I}, E_{T}$ and $E_{R}$ denote the energy flux per unit area cycle of oscillation associated with the incident, transmitted and reflected waves, respectively.

$$
R=\sqrt{\frac{E_{R}}{E_{I}}}, T=\sqrt{\frac{E_{T}}{E_{I}}}, A=\sqrt{1-R^{2}-T^{2}}
$$

\section{2 Numerical Models}

The FEM and DEM models were established with the same dimension and boundary conditions. To sufficiently represent the deformation behavior and stress distribution in the rock mass, the size of the numerical models was determined as $240 \mathrm{~m} \times 200 \mathrm{~m}$ (Fig. 5a). According to the distance to the nuclear facilities, the model of rock mass was divided into two parts, namely the far-field region and the near-field region. Comparing to the farfield region, the rock structure of the near-field region has more direct influences on the dynamic behaviors and safety of nuclear facilities, which is therefore chosen as the target study region in the numerical study. According to the aforementioned in-situ survey results, two sets of parallel joints were set in the near-field region (Fig. 5b), among which the set- 1 joints are persistent throughout the near-field region, playing a major role in the seismic behaviors of the rock mass, while the set- 2 joints are non- 
persistent with orientation perpendicular to set- 1 joints. The spacing of set- 2 joints is 2 times of that of set- 1 joints $\left(S_{2}=2 \times S_{1}\right.$ and $\left.S_{1}=5 \mathrm{~m}\right)$. Note that in Fig. 1, the spacing of joints is around some tens $\mathrm{cm}$, which will lead to a huge amount of joints in the numerical model. The joint spacing which reflects the integrity of rock masses and affects the strength and deformation of rock masses, usually ranges from tens $\mathrm{cm}$ to tens $\mathrm{m}$. At here, the spacing of set- 1 joints was set to $5 \mathrm{~m}$ to shorten the computing time. To study the effect of joint dip angle, the dip angles of set- 1 joints $(\alpha)$ were set as $10^{\circ}, 15^{\circ}, 30^{\circ}, 45^{\circ}, 55^{\circ}, 60^{\circ}, 65^{\circ}$, $75^{\circ}$ and $80^{\circ}$ respectively in DEM models, and $15^{\circ}, 30^{\circ}, 45^{\circ}$, $55^{\circ}, 60^{\circ}$ and $75^{\circ}$ respectively in FEM models.

The upward-propagating seismic wave was input from the bottom of numerical models. In both the DEM and FEM model, the viscous boundary was assigned to the bottom of the numerical models to absorb the dissipating energy, and free-field boundaries were set to the lateral boundaries of the models to allow the propagation of seismic waves out of the models.

A main monitoring point marked as $\mathrm{M}$ was set in the near-field region to estimate the seismic behaviors of the rock mass (Fig. 5a), which is located in the middle of the model with a depth of $35 \mathrm{~m}$. In addition, another 4 monitoring points was set on the central axis of the model, with the depth of $0 \mathrm{~m}, 35 \mathrm{~m}, 100 \mathrm{~m}$ and $190 \mathrm{~m}$ respectively, to investigate the seismic responses of rock foundation at different depths.

\section{Results and Discussions}

\section{1 Seismic Responses of Rock Foundation at Different Depths}

The seismic responses of rock foundation differ at different locations, affected by the transmission distance of

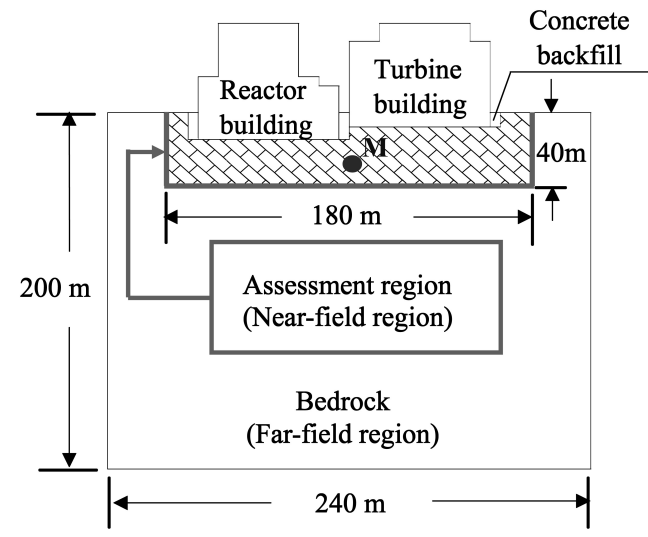

(a) Numerical model and its dimensions

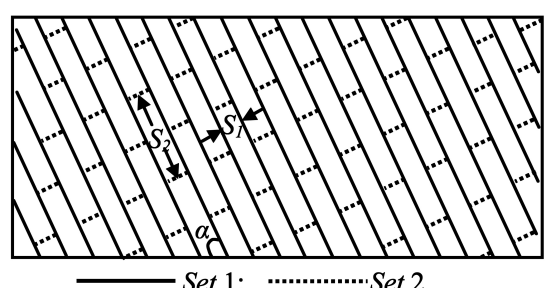

(b) Distribution of joints in the near-field region

Fig. 5 Numerical models and the distribution of joints. seismic waves and the rock mass properties.

Figure 6 shows the horizontal velocity waves at 4 monitoring points (in the case $\alpha=55^{\circ}$ ) obtained from FEM and DEM simulations. In FEM simulations (Fig. 6a), the waveforms at monitoring points with varying depths are consistent except for the difference in maximum amplitudes, and those waves reach their maximum amplitudes almost simultaneously. The DEM results (Fig. 6b) reveal that although the response waves at different locations are similar, some different characteristics still can be confirmed comparing with the FEM results, mainly in two aspects : the amplitudes variation at peaks and troughs of waves are more obvious ; the peaks and troughs of waves appear at different times.

The relationship between the maximum amplitudes of waves and the depths of monitoring points is shown in Fig. 7. The DEM results exhibit a two-stage characteristic. When seismic waves travel in the far-field region $(-200 \mathrm{~m}<d<-40 \mathrm{~m})$, the wave amplitude increases with the increase of transmission distance, due to the amplification effect of the intact rock. However, the amplitude decreases when the seismic wave propagates through the near-field region $(-40 \mathrm{~m}<d<0 \mathrm{~m})$, due to the attenuation effect of joints. The DEM results demonstrate that the intact region and the jointed region of rock mass have different effects on the propagation of seismic waves. However, in the FEM simulation, the maximum amplitudes of waves increase in an approximately linear way with the upward propagation of seismic waves throughout the whole rock foundation. The FEM, considering that the displacements are continuous across

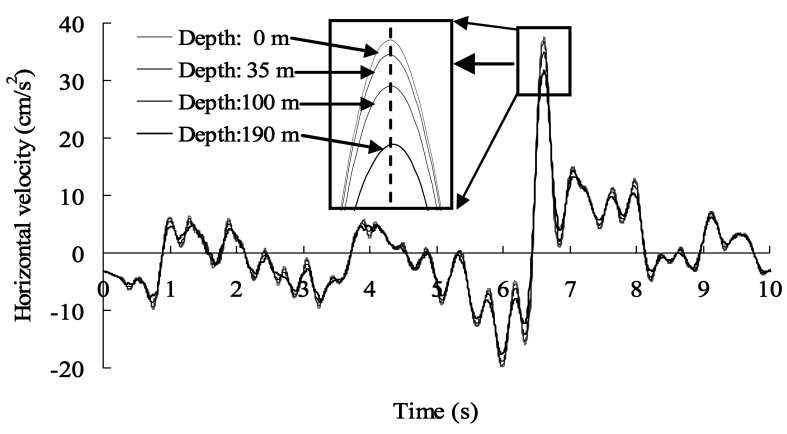

(a) FEM results

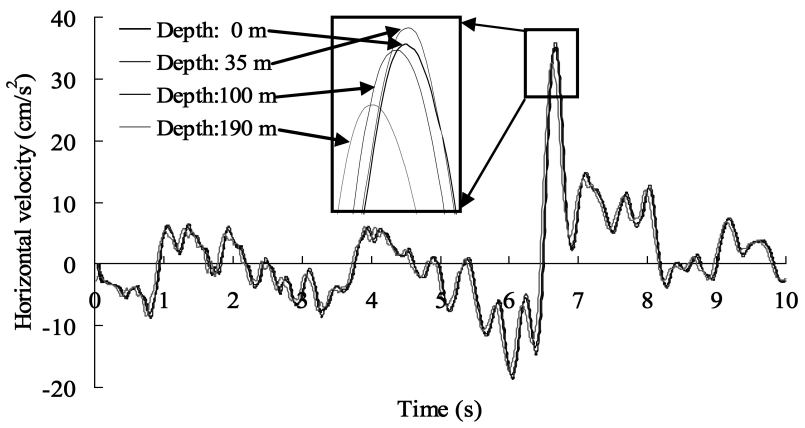

(b) DEM results

Fig. 6 Horizontal velocity waves at the monitoring points with different depths $\left(\alpha=55^{\circ}\right)$. 
the joints due to the continuity principle, cannot well represent the large deformation of joints like sliding and separation, which leads to the energy dissipation during wave transmission. Therefore, the FEM in some extents underestimates the attenuation effect of joints on the propagation of seismic waves.

\section{2 Effect of Joint Dip Angle on Seismic Behaviors of Rock Foundation}

The monitoring point $\mathrm{M}$ is located in the near-field region, close to the nuclear facilities. The seismic behaviors measured at this point can in some contents reflect the dynamic behaviors of the nuclear power plant. During the dynamic simulations, the horizontal velocity, displacement and the horizontal stress, were recorded at the monitoring point, and the peak values of these variables were analyzed.

Figure 8 shows the changes of the maximum horizontal velocity with the dip angle of joints $(\alpha)$ at monitoring point $M$. In all the cases with varying joint dip angles, the maximum horizontal velocities obtained from the FEM simulations (ranging form 36.43 to $36.78 \mathrm{~cm} / \mathrm{s}$ ) are larger than those obtained from the DEM simulations (ranging from 33.30 to $35.69 \mathrm{~cm} / \mathrm{s}$ ), due to that the weakening effect of joints was underestimated in the FEM simulations. The results of the DEM simulations indicate that the change of joint dip angle affects the maximum velocity significantly. For the cases of small angle joints $\left(10^{\circ} \leq\right.$ $\alpha \leq 30^{\circ}$ ), the maximum velocity at point $\mathrm{M}$ decreases with the increase of joint dip angle. Then the maximum velocity gradually increases in the dip angle range of $30^{\circ} \sim 60^{\circ}$, and reaches its peak value $(35.69 \mathrm{~cm} / \mathrm{s})$ when $\alpha=60^{\circ}$. After that, the maximum velocity begins to reduce as the joint dip angle increases $\left(60^{\circ} \leq \alpha \leq 80^{\circ}\right)$. Although the FEM results exhibit a similar varying tendency, the influence of joint dip angle on the horizontal velocity is much weaker than that in the DEM results.

For the purpose of verification, Fig. 8 also lists the results of DEM simulations with a simple harmonic wave (a low-frequency sine wave with the identical maximum amplitude to the Ojiya wave : $f=2.82 \mathrm{~Hz}$ and $A=$ $37.6 \mathrm{~cm} / \mathrm{s}$ ), which agree well with the results obtained by inputting the Ojiya wave, in the aspect of the effect of

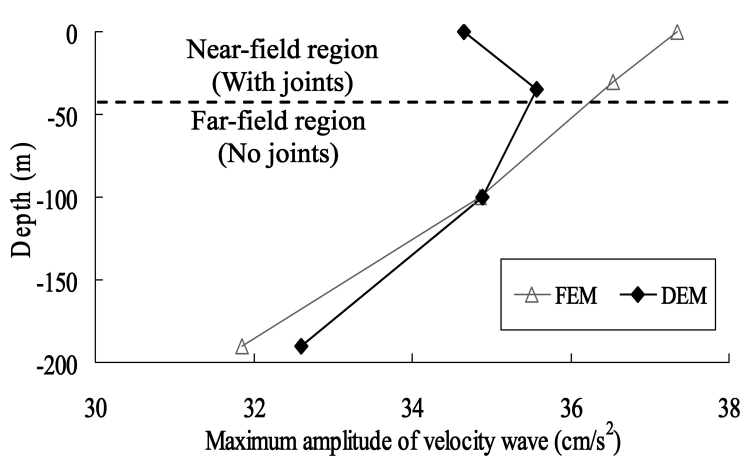

Fig. 7 Relationship between the maximum amplitudes of velocity waves and the depths $\left(\alpha=55^{\circ}\right)$.

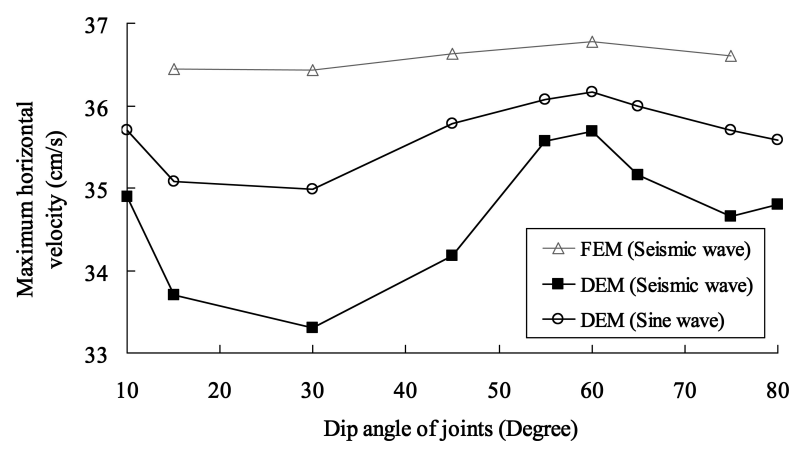

Fig. 8 Relationship between the maximum horizontal velocities with the dip angles of joints at the monitoring point M.

joint dip angle. The horizontal velocity obtained with the sine wave is larger than that obtained with the Ojiya seismic wave, due to that the average amplitude of sine wave is larger than that of the seismic wave.

Figure 9 shows the relationship between the maximum horizontal displacements (absolute value) with the joint dip angles $(\alpha)$ at the monitoring point M. The effects of joints in FEM simulations are not obvious, therefore, only the DEM results are involved in Fig. 9. As the dip angle of joints increases from $10^{\circ}$ to $80^{\circ}$, the maximum displacement at monitoring point $\mathrm{M}$ decreases initially in the cases of small angle joints, then increases and reaches the peak value $(14.68 \mathrm{~cm})$ when $\alpha=60^{\circ}$. The varying tendency of the horizontal displacement is in good agreement with that of the horizontal velocity, since the displacements are derived through the integration of velocity with respect to time in the numerical simulations. The numerical results with the sine wave also exhibit a similar variation trend of the horizontal displacement with the joint dip angle, while the value of displacement is frequency-dependent.

The changes of horizontal velocity and displacement with dip angle of joints at monitoring point $\mathrm{M}$ reflect the influence of joint dip angle on the deformation behaviors of the rock foundation. The results of numerical simulations show that the horizontal velocity and displacement of the rock foundation reach the maximums when the dip angle of joints is $60^{\circ}$. In addition, the cases of small angle joints also have considerable velocities and displacements resulted from horizontal seismic loads.

Due to the high strength of the intact rock, the total deformation of the rock mass is principally governed by the deformation of joints. The deformation of inclined joints consists of two components : the normal deformation (closure or opening of joints) and the tangential deformation (slipping of joints). $\left.{ }^{12)} \sim 16\right)$ With the increase of joint dip angle, the tangential deformation of joints decreases, while the normal deformation increases. For the cases of small angle joints, the tangential deformation of joints accounts for the most portion of the total. Therefore, the slipping of joints can produce a considerable horizontal displacement under horizontal seismic 


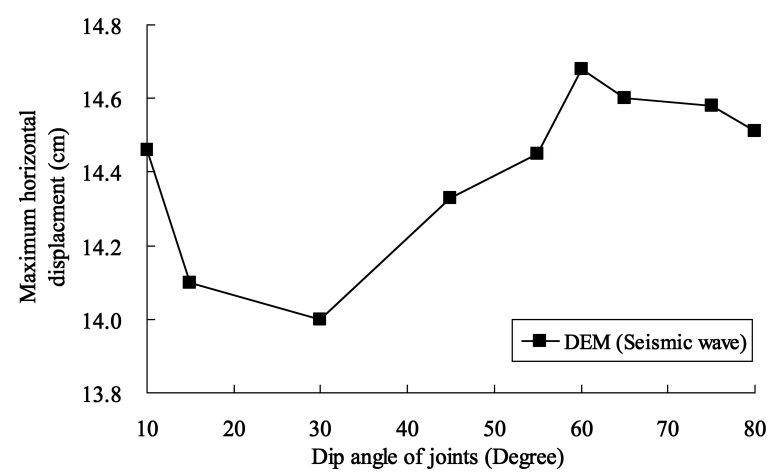

Fig. 9 Relationship between the maximum horizontal displacements with the dip angles of joints at the monitoring point $\mathrm{M}$.

loads. For the cases of large angle joints, the normal deformation of joints contributes to the total deformation primarily. The numerical results indicate that in the case of $\alpha=60^{\circ}$, the total deformation of rock mass reaches the maximum under the combined action of the normal and tangential deformations of joints. The dynamic simulation results of this study have similar tendencies to the static simulation results reported by $\mathrm{Wang}^{16)}$ and Jiang, ${ }^{25)}$ demonstrating that the joint dip angle has analogous effects on the deformation of rock masses under static and dynamic loading conditions.

Figure 10 shows the change of the maximum horizontal stress with the joint dip angle at monitoring point $\mathrm{M}$ obtained from the DEM simulations, where positive values represent compressive stresses. For all the cases with different dip angles of joints, the maximum horizontal stresses range from 0.71 to $1.27 \mathrm{MPa}$.

The change of joint dip angle affects the horizontal stresses of rock foundation significantly. For the cases of small angle joints $\left(15^{\circ} \leq \alpha \leq 30^{\circ}\right)$, the horizontal stress decreases with the increase of $\alpha$. For the cases of large angle joints, the horizontal stress reaches the peak when $\alpha=60^{\circ}$. The influence of joint dip angle on the horizontal stress of rock foundation corresponds well with its influence on the deformation behaviors of rock mass (Figs. 8 and 9). The horizontal deformation of the rock foundation is principally governed by the horizontal stress of rock masses. Around the dip angle of $60^{\circ}$, the horizontal stress reaches the peak, resulting in the maximum deformation of rock masses.

\section{Conclusions}

The dynamic behaviors of the rock foundation subjected to seismic loads concerns the safety of nuclear power plants. In this study, the FEM and DEM simulations were performed to investigate the seismic responses of rock foundation to a real seismic wave obtained in the Chuetsu offshore earthquake (Niigata, 2007), taking into account the effect of joint dip angle on the seismic behaviors of rock mass.

Response waves of velocity at monitoring points with different depths were obtained. In the DEM simulations, the amplitude of the response wave increases when seismic waves travel through the intact far-field region of rock foundation, due to the amplification effect of the intact rock, while the wave amplitude decreases when seismic waves propagate through the jointed near-field region, due to the attenuation effect of joints. In the FEM simulation, the maximum amplitudes of waves increase in an approximately linear manner with the upward propagation of seismic waves throughout the whole rock foundation, indicating that the FEM in some extents underestimates the attenuation effect of joints on the propagation of seismic waves. These differences between DEM and FEM are mainly due to their different ways of solving the same equations of motion and the different treatments to the deformation of joints.

The change of joint dip angle has significant effects on the seismic behaviors of the rock foundation. The maximum amplitudes of the velocity and displacement waves at the monitoring point in jointed rock mass initially decrease when the joint dip angle increases from $10^{\circ}$ to $30^{\circ}$, then increase and reach the peak values when $\alpha=$ $60^{\circ}$, due to the combination of normal and tangential deformations of joints. In addition, the small angle joints $\left(\alpha=10^{\circ}\right)$ can also result in considerable horizontal deformation due to the large tangential deformations of joints. The influence of joint dip angle on the horizontal stress of rock foundation corresponds well with its influence on the deformation behaviors of rock mass. Therefore, the joints with the dip angle around $60^{\circ}$ as well as the small angle joints could lead to large deformations of rock mass when subjected to shear waves, which requires attentions in engineering practices.

At present, the deformation and failure mechanisms of the jointed rock foundation subjected to seismic loads are still not well understood. Future studies will focus on the mechanical and failure behaviors of rock foundation during earthquakes, taking into account the effect of the geometrical distribution of rock joints like dip angle and spacing.

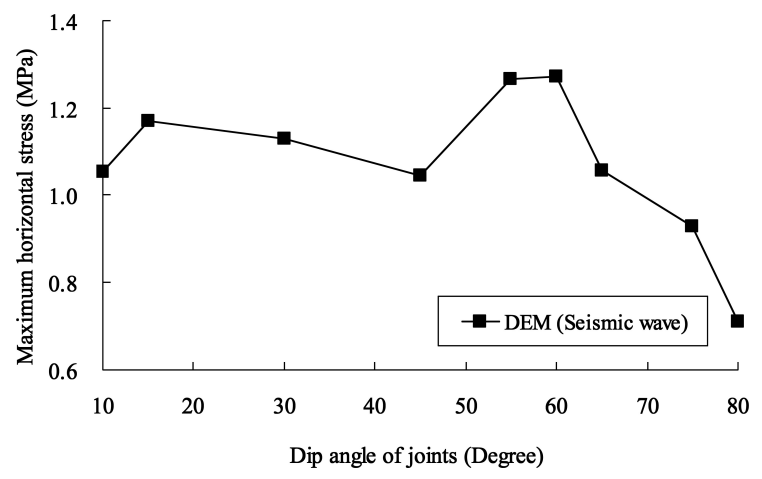

Fig. 10 Relationship between the maximum horizontal stresses with the dip angles of joints at the monitoring point M. 


\section{References}

1) International Atomic Energy Agency, "Nuclear power plant information”, http : //www.iaea.org/ (2011).

2 ) Japan Society of Civil Engineers, "Dynamic analysis and seismic design”, pp.3-5 (1989) Japan Gihodo Press.

3 ) P. B. Schnabel, J. Lysmer and H. B. Seed, "SHAKE : A computer program for earthquake response analysis of horizontally layered sites”, USA. EERC University of California, Berkeley (1972).

4 ) H. B. Seed, R. T. Wong, I. M. Idriss and K. Tokimatsu, "Moduli and damping factors for dynamic analyses of cohesionless soils”, Journal of Geotechnical Engineering, Vol.112, No.11, pp.1016-1032 (1986).

5 ) I. M. Idriss, H. B. Seed and N. Serff, "Seismic response by variable damping finite elements", Journal of Geotechnical Engineering Division, Vol.100, No.1, pp.1-13 (1974).

6 ) S. Kinoshita, "Spectral characteristics of bedrock motion in the tokyo metropolitan area", Proceeding of Japan Society of Civil Engineers, No.344/I-1, pp.51-56 (1984).

7 ) M. Kamiyama and E. Yanagisawa, "A statistical model for estimating response spectra of strong earthquake ground motions with emphasis on local soil condition", Soils and Foundations, Vol.26, No.2, pp.16-32 (1986).

8 ) C. Chen, M. Lou and S. Tao, "Discussions on two-dimensional finite element analysis of seismic response”, Technology for Earthquake Disaster Prevention, Vol.1, No.4, pp.292-301 (2006).

9) N. Ushiyama, H. Taniyama and F. Tsunoda, "Concussional movement of the Rokko fault block in Kansai and its dynamic response analysis for seismic isolation block system”, Earth Science, Vol.26, pp.343-354 (2009).

10) T. Lu, Q. Yang, X. Geng, L. Yang, L. Yang and H. Li, "Study of influence of rock hardness on characteristic of seismic response of bedrock-foundation of nuclear power plants", Rock and Soil Mechanics, Vol.31, No.4, pp.1319-1325 (2010).

11) Y. Jiang, B. Li and Y. Yamashita, "Simulation of cracking near a large underground cavern in a discontinuous rock mass using the expanded distinct element method", International Journal of Rock Mechanics and Mining Sciences, Vol.46, pp.97-106 (2009).

12) H.J. Schneider, "The friction and deformation behaviour of rock joints”, Rock Mechanics, Vol.8, pp.169-184 (1976).

13) S. C. Bandis, A. C. Lumsden and N. R. Barton, "Fundamentals of rock-joint deformation", International Journal of Rock Mechanics and Mining Sciences \& Geomechanics Abstracts, Vol.20, No.6, pp.249-268 (1983).
14) N.R. Barton, "Deformation phenomena in jointed rock", Geotechnique, Vol.36, No.2, pp.147-167 (1986).

15) Z. Sun, C. Gerrard and O. Stephansson, "Rock joint compliance tests for compression and shear loads", International Journal of Rock Mechanics and Mining Sciences \& Geomechanics Abstracts, Vol.22, No.4, pp.197-213 (1985).

16) T. T. Wang and T. H. Huang, "A constitutive model for the deformation of a rock mass containing sets of ubiquitous joints”, International Journal of Rock Mechanics and Mining Sciences, Vol.46, pp.521-530 (2009).

17) J. G. Cai and J. Zhao, "Effects of multiple parallel fractures on apparent attenuation of stress waves in rock masses", International Journal of Rock Mechanics and Mining Sciences, Vol.37, pp.661-682 (2000).

18) J. Zhao and J. G. Cai, "Transmission of elastic P-waves across single fractures with a nonlinear normal deformation model”, Rock Mechanics and Rock Engineering, Vol.34, No.1, pp.3-22 (2001).

19) X. B. Zhao, J. Zhao, A. M. Hefny and J. G. Cai, "Normal transmission of S-wave across parallel fractures with coulomb slip behavior", Journal of Engineering Mechanics, Vol.132, No.6, pp.641-650 (2006)

20) B. Li, Y. Jiang, Y. Tanabashi and Y. Yamashita, "Behavior of large scale underground cavern located in jointed rock masses evaluated by using distinct element method", Soils and Foundations, Vol.50, No.5, pp.609-621 (2010).

21) C. Zhang, O. A. Pekau, F. Jin and G. Wang, "Application of distinct element method in dynamic analysis of high rock slopes and blocky structure”, Soil Dynamics and Seismic Engineering, Vol.116, pp.385-394 (1997).

22) Structure and Planning Institute of Japan, "User manual of the seismic response analysis program for stratified soil layers : k-SHAKE” (2005) Tokyo.

23) Itasca Consulting Group Incorporation, "Universal distinct element code : Theory and background" (2004) Minnesota, USA.

24) Structure and Planning Institute of Japan, "User manual of the two-dimensional dynamic interaction analysis program for ground and structure : SuperFLUSH/2D" (2005) Tokyo.

25) Y. Jiang, Y. Tanabashi, B. Li and J. Xiao, "Influence of geometrical distribution of rock joints on deformational behavior of underground opening”, Tunnelling and Underground Space Technology, Vol.21, pp.485-491 (2006). 